Burdett, Pino, Moghaddam, \& Schröder (2019). It sounds silly now, but it was important then

\title{
"It sounds silly now, but it was important then": supporting the significance of a personal experience in psychotherapy
}

\author{
Mark Burdett, Derbyshire NHS Healthcare Foundation Trust, $\mathrm{UK}^{1}$ \\ Marco Pino, Loughborough University, UK \\ Nima Moghaddam, University of Nottingham, UK \\ Thomas Schröder, University of Nottingham, UK
}

\begin{abstract}
The article examines a previously undocumented practice whereby psychotherapy clients support the significance of their experience against the background of how it can otherwise be heard. This practice is the phrase "it sounds X, but Y" (e.g., "which sounds silly now, but was like important then"). We call this an SXB-contrast. We used conversation analysis to examine 21 instances of this phenomenon, identified in 12 audio-recorded individual psychotherapy sessions involving 10 clients and 8 therapists.

Clients use SXB-contrasts to mark part of their talk as delicate, specifically by voicing an unsympathetic hearing of that talk whilst supporting its experiential significance. Evidence for our claims comes from clients' use of SXB-contrasts in association with practices of speech delivery (e.g., laughter) and self-repair operations which also establish a part of their talk as delicate. Therapist responses provide additional supporting evidence. The study contributes to understanding how clients can use meta-talk to convey the meaning of their experiences in therapy whilst also making available their own emerging awareness of the multiple meanings of those experiences.
\end{abstract}

Keywords: Conversation analysis, delicacy, experience, meta-talk, psychotherapy

Burdett, M., Pino, M., Moghaddam, N., \& Schröder, T. (2019). "It sounds silly now, but it was important then": Supporting the significance of a personal experience in psychotherapy. Journal of Pragmatics. doi: 10.1016/j.pragma.2019.05.007

\footnotetext{
${ }^{1}$ For correspondence: mark.burdett@nhs.net.
} 
Burdett, Pino, Moghaddam, \& Schröder (2019). It sounds silly now, but it was important then

\section{Introduction}

Tellers of personal troubles commonly face two practical tasks: promoting the alignment of their interlocutors as recipients of their troubles and helping them appreciate the nature of those troubles (Jefferson, 1981, 1988). These tasks have special prominence in psychotherapy. Psychotherapy relies on clients' ability and willingness to share their past and present experiences, which form the primary source of materials for the therapeutic process (Voutilainen \& Peräkylä, 2014). Clients use a range of socio-interactional practices to convey their experiences.

In this paper, we examine a previously undocumented practice that clients use to convey their experiences in psychotherapy. This practice is a contrastive remark by which clients voice an unsympathetic reception of a part of their talk - and the experience described thereinwhilst upholding its significance.

\subsection{SXB-contrasts, intersubjectivity and clients' orientations to 'others'}

The practice we examine marks a spontaneous (i.e., not solicited by the therapist) shift from talk describing a personal experience (i.e., talk reporting life events and associated thoughts and emotions) to commenting on that talk. With this practice, clients contrast a possible way of hearing their own talk with a statement of the significance of the experience described therein (e.g., "which sounds silly now, but was like important then"). The first part of the contrast takes different shapes, including "sounds silly now", "I don't want to sound really ungrateful", and "I make that sound weird". In common to these forms is that clients articulate how a part of their own talk may 'sound'. They then go on to contrast that hearing, which is unsympathetic, with a statement that upholds the significance of the experience they are describing (e.g., "but was like important then"). We propose that, across variations in design, the contrasts we examine implement a common action: supporting the significance of a personal experience against an unsympathetic reception of it (i.e., how it may 'sound'). With "unsympathetic" we intend to capture a range of negative reactions to clients' talk, which clients themselves voice, including its treatment as trivial or as morally inappropriate. Despite the variations in form mentioned above, for purposes of exposition - and based on the proposal of a common action implemented through those forms - we term this practice a "sounds X but" contrast; referred to as $S X B$-contrast hereon.

SXB-contrasts are practices by which clients convey the meaning of their experiences and thereby promote a sense of intersubjectivity in therapy-intersubjectivity being "the maintenance of a world (including the developing course of the interaction itself) mutually understood by the participants as some same world" (Schegloff, 1991, p. 151, emphasis in the original). From the standpoint of ethnomethodology, "the intersubjective intelligibility of actions ultimately rests on a symmetry between the production of actions on the one hand and their recognition on the other" (Heritage, 1984, p. 179). Inherent to the production element of social action is the principle of recipient design, according to which "the talk by a party in a conversation is constructed or designed in ways which display an orientation and sensitivity to the particular other(s) who are the co-participants" (Sacks et al., 1974, p. 727). With SXBcontrasts, clients exhibit sensitivity to the "others" who can react to their talk. However, we suggest that with SXB-contrasts clients exhibit an orientation to a possible audience beyond the "particular other" with whom they are interacting (i.e., the therapist). SXB-contrasts are generally equivocal in terms of whether they anticipate an unsympathetic reception of the client's talk from the therapist, a more generalised unsympathetic reception from 'others' outside the immediate context of the interaction, the client's own reaction to their own talk, or a combination of some or all these options. For an initial illustration, consider Extract 1. A client, Anna, is telling her therapist about her experience of being bullied at school. Our focus is on lines 7-9. 
Burdett, Pino, Moghaddam, \& Schröder (2019). It sounds silly now, but it was important then

Extract 1 (fragment of Extract 2, examined in more detail later)

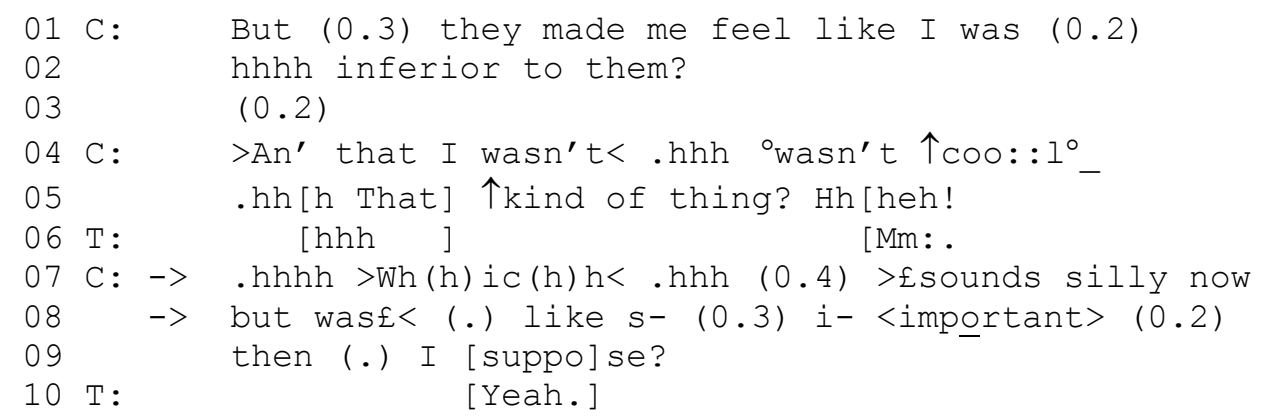

After articulating her experience (lines 1-5) Anna comments: ">Wh(h)ic(h)h $<$.hhh $(0.4)>£$ sounds silly now" (line 7). This is the first part of an SXB-contrast-its second part being "but was $£<$ (.) like s- (0.3) i- <important $>$ (0.2) then (.) I [suppo]se?" (lines 8-9). With "which sounds silly now", Anna proposes that her talk can be heard in a certain way, with no claim about who in particular could hear it in that way. She leaves this open. This is a recurrent feature of SXB-contrasts: clients evoke a generalised (unattributed) reception of their talk. They voice how their talk can sound to an unsympathetic audience, which can include the therapist and, importantly, in some cases (including Extract 1) the client themselves.

Anticipation of others' responses plays a central role in some theories of social action. Mead's (1934/62) notion of a "generalised other" encapsulates the ways in which people design their actions by anticipating others' possible responses. In Mead's theory, people's orientation to and internalising of the normative expectations of the social community at large-the generalised other-play a key role in both the development of mind and the building, maintenance, and modification of social orders and institutional realities.

Goffman's (1959) dramaturgical analogy of social interaction sees people as constantly performing on a social stage. Social actions embody a constant preoccupation with managing others' impressions whilst trying to achieve one's own goals. According to Goffman, anticipation of others' responses lies at the heart of the ways in which people design their social actions. In the sequences of talk we examine in this article, clients also appear to engage in what Goffman (1955) termed "face-work"- a constellation of actions by which social actors manage others' impressions about them.

In our examination of SXB-contrasts, we follow the tenets of conversation analysis (CA). Using this approach, we do not treat clients' SXB-contrasts as indicating an abstract orientation to a generalised other and the normative expectations associated with it. Rather, we ask what actions clients implement by evoking the perspective of an unsympathetic audience (to whom their talk may 'sound' in a certain way). We propose that clients use SXB-contrasts to mark a part of their talk as delicate; they do this by conveying that it can be received in unsympathetic ways whilst also upholding its significance. With this, they convey the meaning of their experience in a multi-layered way. They support its significance whilst exhibiting reflective awareness that some aspect of it can be regarded as socially or morally problematic, or difficult to understand.

\subsection{SXB-contrasts as meta-talk}

With SXB-contrasts, clients comment on a part of their talk. SXB-contrasts are akin to what have been previously termed meta-language (Lucy, 1993) and narrative reflexivity (Auburn, 2005). Auburn (2005) examined cases of offenders commenting on their own talk within group sessions for prisoners undergoing a sex offender treatment programme. Offenders sometimes 
shifted from narrating past events to commenting on their own narratives, such as in: "I mentioned it because it, you know, it has got some relevance" (Auburn, 2005, p. 704). They anticipated negative interpretations - negative in the context of their treatment programmeand pre-emptively denied their validity. We will show that SXB-contrasts similarly convey an unsympathetic reception of clients' talk (see also Verschueren, 2000 and Hewitt \& Stokes, 1975). However, they do not necessarily discount the validity of that hearing. Rather, the clients in our data show awareness that their talk can be received unsympathetically whilst they support the significance of the experience described therein. In doing so, they show that they hold a multi-faceted perspective on the meaning of their own experience.

SXB-contrasts can also be regarded as a form of self-reflective talk, whereby people "take an observing, evaluating or interpreting position towards their own actions and experiences" (Logren et al., 2017, p. 422). As an example of this, Logren et al. (2017) show the case of a client attending a nutritional support group who reflects on her habit of quickly eating pastries in the car as "the most pitiful thing that I like do in my life" (pp. 431-432). This self-reflection displays the client's orientation to group-level normative expectations regarding desirable behavioural changes. The SXB-contrast is also self-reflective in that clients adopt the perspective of an unsympathetic audience in order to voice an evaluation of their own experience; in doing so, they display an orientation to social expectations about what counts as an intelligible and appropriate experience. However, SXB-contrasts are not just practices whereby clients voice a reflection on their experience; they are practices whereby they comment on a part of their talk, which describes an aspect of their experience. They are form of meta-talk.

In this paper, we examine the structure and functions of SXB-contrasts. Our study contributes to understandings of how psychotherapy clients use meta-talk to convey the meaning of their experiences. It also contributes to understandings of delicacy in interaction by examining a particular way in which speakers can mark their talk as delicate: evoking an unsympathetic reception of that talk as the background against which its experiential significance can be properly appreciated.

\section{Method}

\subsection{Conversation analysis}

Conversation Analysis (CA) is a methodological approach that allows one to examine how social actions are accomplished via different forms of talk in interaction (Hutchby \& Wooffitt, 2008). This includes actions that people deliver through expanded stretches of talk, such as in story-tellings (e.g., Holt, 2012; Jefferson, 1988; Mandelbaum, 2013; Schegloff, 2007). This makes CA suited for the purpose of our study, which is to examine the structure and function of an interactional practice - the SXB-contrast-which clients often use within extended narrations and descriptions (see Madill et al., 2001).

CA research is undertaken in several steps (Hutchby \& Wooffitt, 2008; ten Have, 2007). The data are explored using "unmotivated looking" (Hutchby \& Wooffitt, 2008; Schegloff, 1996), that is, without pre-conceived ideas about the nature of the phenomena contained therein (ten Have, 2007). Collections of recurrent communicative actions and patterns are then built and transcribed using a system devised by Jefferson (2004a; see appendix). The cases within the collection are then examined in more detail to cross-compare and analyse trajectories of talk and to establish shared and divergent features of specific practices. Analysis proceeds through in-depth case-by-case analysis on a cumulative basis in order to identify the common features of the communicative practices under examination as well as deviant and negative cases (ten Have, 2007). 
Burdett, Pino, Moghaddam, \& Schröder (2019). It sounds silly now, but it was important then

\subsection{Data}

We performed a secondary data analysis of an existing corpus of audio recordings collected at a UK university counselling and psychotherapy service established as a research clinic. The clinic offered free counselling and psychotherapy to university staff and students - sometimes referred by other university services - in return for their participation in research. The therapists were student therapists, applying humanistic and psychodynamic therapeutic approaches under the supervision of experienced clinicians. The clinic provided help for a range of problems, including stress, bereavement, and relationship issues; but not for more complex presentations involving domestic violence, alcohol abuse, or severe mental health difficulties. In the sessions we examined (see section 2.3), clients discussed a range of difficulties including bereavement, depression, social anxieties, family pressures, and low selfesteem.

The corpus consisted of 342 audio-recorded individual sessions undertaken by 10 therapists with 19 clients; each client worked with the same therapist during their therapy. Therapy length varied. The range was $2-40$ sessions, with a mean of 18 ( $\mathrm{SD}=11.7$; median $=$ 13). Each session lasted approximately 50 minutes. Participants had given consent for secondary data analysis, and ethical approval was obtained for the current study in 2016. To preserve confidentiality, the people and place names in our extracts are pseudonyms.

\subsection{Analytic strategy}

We randomly sampled one session from each therapy using RANDBETWEEN in Microsoft Excel (2016). We systematically searched for instances of explicit client meta-talk in these sessions (i.e., cases where clients explicitly commented upon their own talk).

After identifying different types of meta-talk, we decided to focus on SXB-contrasts. In order to identify additional instances of SXB-contrasts, we randomly sampled and searched two additional sessions in each of the 19 therapies where possible (one therapy only consisted of two sessions). Our data set for this study therefore consists of 56 sessions in which we identified 21 instances of client SXB-contrasts. Our approach to the selection of sessions was dictated by time and resource considerations. One consequence of our search procedure is that we cannot establish whether clients' use of SXB-contrasts varied (e.g., increased or decreased) during their therapy. The points we make in this paper are independent of the stage of advancement of the clients' therapy (although we acknowledge that situating the use of SXBcontrasts within that broader context could constitute an important extension of the analysis).

SXB-contrasts appear to happen relatively rarely (21 instances in 56 systematically screened sessions). Due to time and resource constraints, we were not able to collect and compare other forms of talk which may (or may not) have similar functions (e.g., formulations about how some things may 'seem' rather than 'sound'). There may be other practices through which clients achieve similar outcomes as the ones we document in this paper, making it difficult to speculate about the relative infrequency of SXB-contrasts. Nevertheless, in this paper we support the proposal that the SXB-contrast constitutes a clearly defined practice with robust interactional patterns. Our analyses show that clients use SXB-contrasts to deal with specifiable emerging problems within their therapeutic interactions; we propose that examination of such problems and their solutions contributes significantly to understandings of therapeutic processes.

Table 1 provides client and therapist characteristics for the therapies where clients use SXB-contrasts as well as for the wider data set. This is meant to show that SXB-contrasts are used by different clients with different therapists in the data set; the distribution of genders (female and male) and roles (university student and staff) of the clients using SXB-contrasts roughly reflects the distribution of genders and roles of the clients in the wider data set. We provide this as background information with no claim about the generalisability of our findings; 
Burdett, Pino, Moghaddam, \& Schröder (2019). It sounds silly now, but it was important then

also, provision of this socio-demographic information is not meant to suggest that participants' use of and responses to SXB-contrasts are linked to their observable orientations to gender or role (no such links have emerged in our analyses).

\begin{tabular}{lll}
\hline & With SXB-contrasts & Overall data set \\
\hline Therapy sessions & $12(21 \%)$ & $56(100 \%)$ \\
Total & $10(53 \%)$ & $19(100 \%)$ \\
$\frac{\text { Clients }}{\text { Total }}$ & $2(20 \%)$ & $6(32 \%)$ \\
$\begin{array}{l}\text { Gender } \\
\quad \text { Male (\%) }\end{array}$ & $13(68 \%)$ \\
$\quad$ Female (\%) & $8(80 \%)$ & $17(89 \%)$ \\
Client as student or staff & $9(90 \%)$ & $2(11 \%)$ \\
$\quad$ Student (\%) & $1(10 \%)$ & 10 \\
$\quad$ Staff $(\%)$ & 9 & \\
Therapists & & $2(20 \%)$ \\
Total & & $8(80 \%)$ \\
Gender & $2(22 \%)$ & \\
$\quad$ Male (\%) & $7(78 \%)$ & \\
$\quad$ Female $(\%)$ & & \\
\hline
\end{tabular}

Table 1. Participant characteristics.

\section{Results}

With SXB-contrasts, clients shift from reporting past or present experiences to commenting on a part of their own talk. We examine the common actions implemented through SXB-contrasts as well as variations associated with differences in their design (e.g., "sounds X" in Extract 2 versus "I don't want to sound X" in Extract 3).

With the "sounds X" part of the contrast, clients voice an unsympathetic reception of their talk and the experience described therein - for instance, that it sounds "silly" (Extract 2). With the "but Y" part of the contrast, clients support the significance of their experience against the voiced unsympathetic reception-for instance, "but was like important then" (Extract 2). In this way, clients treat an aspect of their talk as delicate. With "delicate", we mean to capture the sense in which clients treat part of their own talk as vulnerable to attracting less than favourable reactions. In this way, clients also exhibit awareness of the multiple possible meanings of their experience; specifically, that it has significance for them-as voiced in the 'but $\mathrm{Y}$ ' part of the contrast - whilst also having the potential to meet an unsympathetic reception with those who might hear the description of that experience - the audience evoked in the 'sounds X' part of the contrast.

We provide three sources of evidence for our argument: clients' use of SXB-contrasts in association with other practices that mark parts of their talk as delicate; clients' use of SXBcontrasts within segments of self-repair; and therapists' responses. Before undertaking these steps, we show that clients deploy SXB-contrasts in two ways: retrospectively and prospectively.

\subsection{Retrospective and prospective SXB-contrasts}

Clients use SXB-contrasts prospectively when they comment on a part of their talk before articulating it (11/21 cases in our collection) and retrospectively when they comment on a part 
of their talk after articulating it (7/21 cases). Three cases display mixed prospective and retrospective features; we do not present these here due to space considerations.

Extract 2 illustrates a retrospective SXB-contrast. The client (Anna) has been talking about how she used to be bullied during secondary school.

Extract 2. 'Anna'. Session 10, 50:31-52:18. Therapist A.

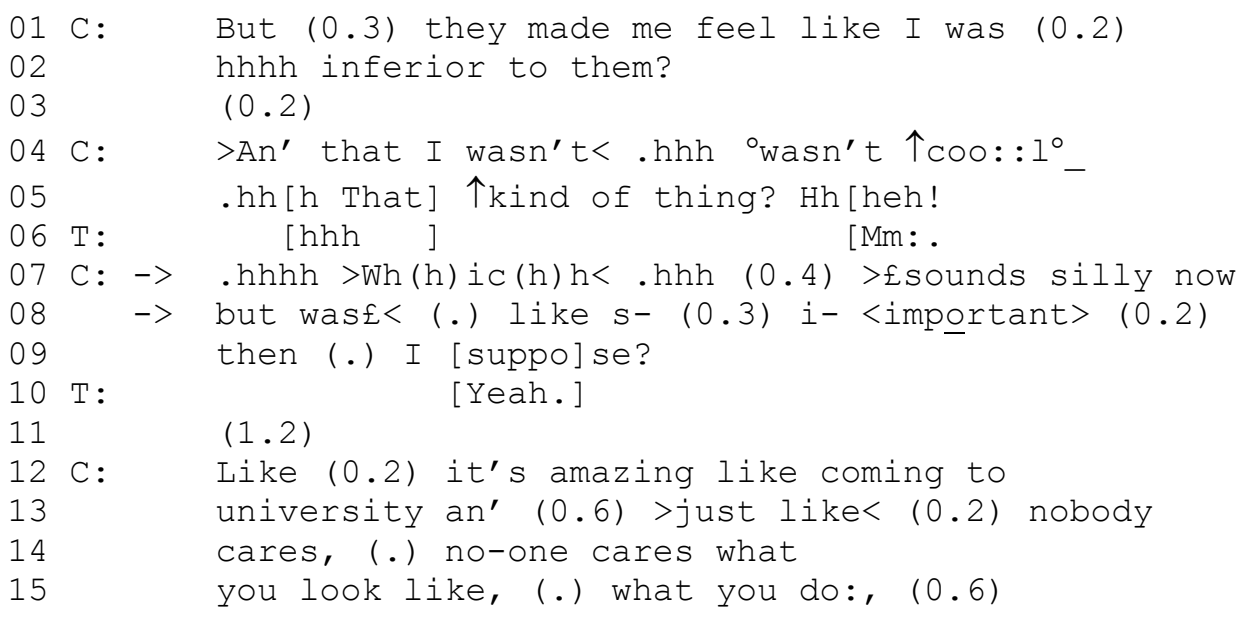

At lines 1-4, Anna reports how other students made her feel. In doing so, she makes available her emotional experience at the time of the reported events. Anna uses an SXBcontrast at lines 7-9. The connective "which" ties the contrast to her previous talk at lines 4-5 and thereby grammatically marks the SXB-contrast as a retrospective one. With the "sounds X' part of the contrast, Anna voices an unsympathetic reception of her talk ("sounds silly now") and the emotional experience described therein. The use of "silly" establishes Anna's emotional response at the time of the reported events as an overreaction to what could now be seen as a trivial problem; that the other students' attitudes towards her made her feel like she "wasn't cool" (line 4). With the 'but Y' part of the contrast, Anna nevertheless supports the experiential significance of that feeling. The juxtaposition of two time-frames ("now" and "then") reinforces the contrast between the time of the reported events (when they were experienced as important) and the present moment (when they can be regarded as trivial).

"Sounds silly" voices a hearing of Anna's talk without attributing that hearing to anyone in particular; this is what we mean to capture with the notion of an unsympathetic audience being evoked by the SXB-contrast. For instance, Anna does not attribute that possible hearing to the therapist (as other forms hypothetically would do, such as 'it may sound silly to you') or to other people, including herself. "Sounds silly" has a certain equivocality to it. It does not claim that Anna's talk sounds "silly" to herself, to the therapist, or to other people; however, it allows for all these possibilities. In doing so, Anna conveys that she holds a multifaceted perspective with regards the meaning of her experience. She supports its significance whilst displaying awareness that it can be treated as trivial.

Extract 3 illustrates a prospective SXB-contrast. The client, Sam, has been talking about how he struggles to focus on his course, having been assaulted and hospitalised before the start of term.

Extract 3. 'Sam'. Session 1, 20:56-21:55. Therapist A.

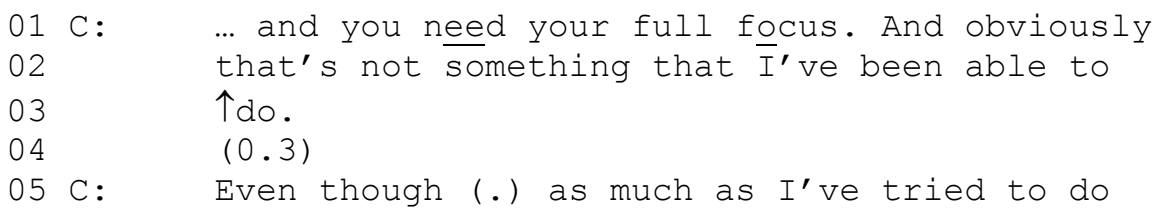




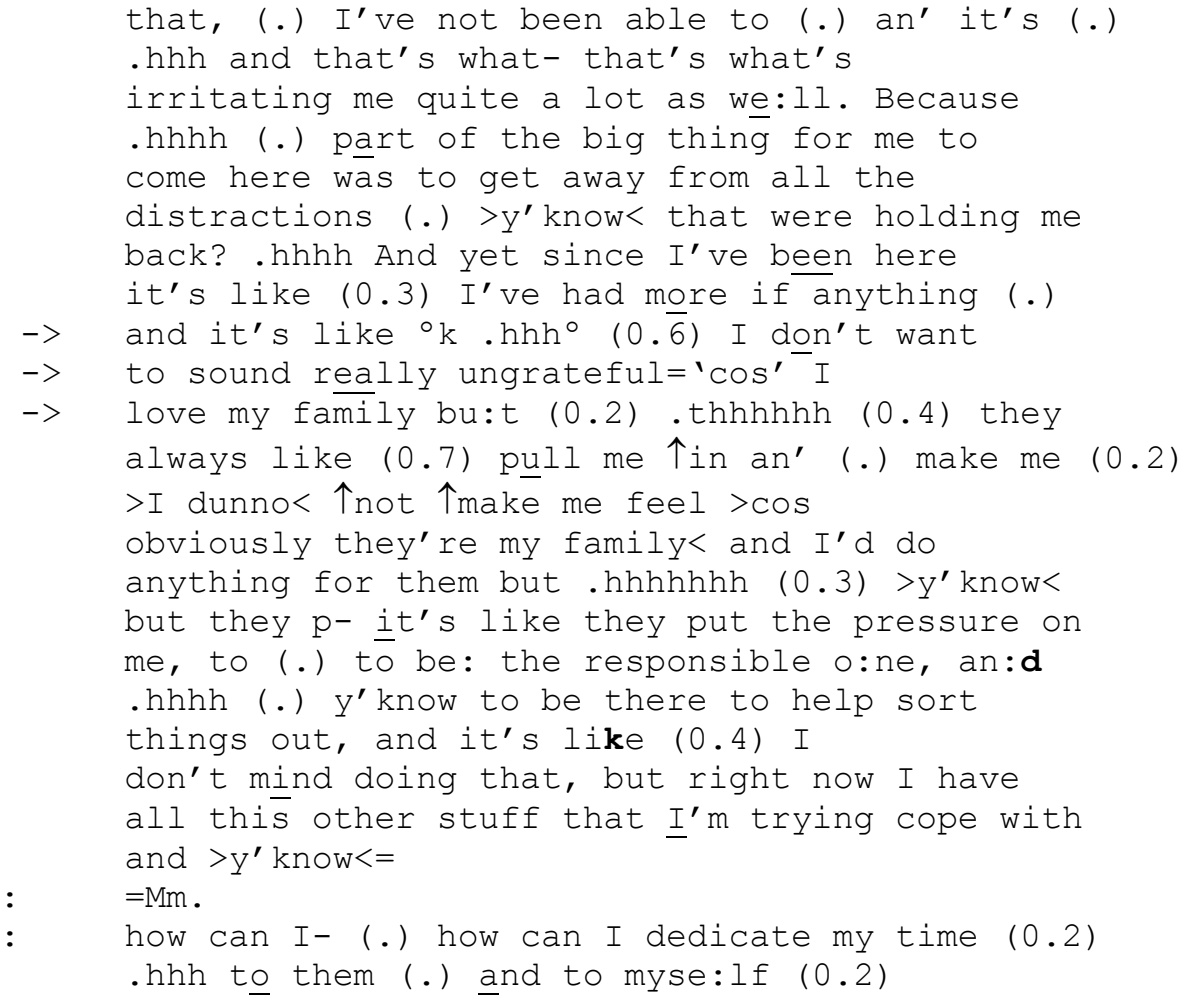

Sam describes some personal struggles at lines 1-13. At line 14, he shifts from reporting his experiences to commenting on a part of his own talk using an SXB-contrast. Sam uses the SXB-contrast to comment on a part of his talk that he has not articulated yet. With the "sounds X' part of the contrast, Sam anticipates the possibility of being considered "ungrateful" because of what he is about to say ("I don't want to sound really ungrateful"). He goes on to counterbalance that unsympathetic hearing with " "cos I love my family". In this way, the 'sounds X' part of the contrast pre-frames Sam's upcoming talk as a complaint about his family. Then, with the 'but Y' part of the contrast, Sam articulates the projected complaint, (from line 16) by reporting that his family are a source of distraction from his studies, as well as a source of emotional pressure. Sam does not use the SXB-contrast to abandon his projected complaint. Rather, Sam voices an unsympathetic reception of that complaint before going on to articulate it.

The design of the contrast in Extract 3 shows some distinctive features. "I don't want to sound X" is different from "[it] sounds X" in Extract 2. The format that Sam uses appears to position him outside the audience whose perspective he is voicing. "I don't want to sound really ungrateful "cos I love my family" anticipates and pre-emptively counterbalances the possibility of a negative reception from others, possibly including the therapist (however, note that "I don't want to sound" does not specifically attribute an unsympathetic hearing to the therapist but, rather, leaves this indeterminate). The upgraded formulation "really ungrateful" further conveys Sam's orientation to a negative moral judgment that others could cast on him for complaining about his family. With the use of "obviously" (line 19), Sam further displays awareness of - and perhaps deference to-social expectations about how a student who is being financially supported by his family should talk about them.

Extracts 2 and 3 illustrate that the particular form of the SXB-contrast adjusts the boundaries of the audience being evoked through it - in terms of whether the client positions themselves as part of that audience (as in Extract 2) or not (as in Extract 3). The contrasts also differ in terms of the perspective they voice; for they can raise the possibility that the client's experience or perspective is treated as trivial (Extract 2) or as morally inappropriate (Extract 
Burdett, Pino, Moghaddam, \& Schröder (2019). It sounds silly now, but it was important then

3). Across these variations, clients consistently use SXB-contrasts to uphold the significance of their experience whilst displaying awareness that it can also be received unsympathetically.

\subsection{SXB-contrasts as markers of delicacy: evidence from aspects of speech delivery}

SXB-contrasts frame a portion of the client's talk as delicate; delicate enough to warrant the momentary suspension of an ongoing description or narrative in order to comment on it. We use the term "delicate" to indicate that clients themselves treat a part of their own talk as vulnerable to attracting negative evaluations or inferences. One source of support for this claim is that clients use SXB-contrasts in association with other practices that also convey delicacy. Here, we focus on clients' use of laughter and other aspects of speech delivery - such as a 'smiley' voice quality - in association with SXB-contrasts.

In Extract 2, above, Anna reports that she used to think she "wasn't cool" (line 4) because of how other students treated her. She delivers the "wasn't cool" element with a soft voice and a higher pitch (on "cool"). We hear this as taking a jocular or light-hearted stance on that past experience; this is supported by the therapist's brief laughter in response (start of line 6). Anna appears to distance herself from that past experience. This stance is compatible with the one she is going to convey through the SXB-contrast: that her past experience, which was significant at the time of the reported events, could now be regarded as somewhat less momentous.

Anna laughs at the end of line 5. She then intersperses the start of her talk containing the SXB-contrast (line 7) with two bursts of laughter (symbolised in the transcript with "(h)"; Potter \& Hepburn, 2000). She produces the first part of the SXB-contrast with a 'smiley' voice quality (shown by “ $£ ”)$. Jefferson (1984) proposed that troubles-tellers use laughter to show that they can take their troubles lightly - that they are not overwhelmed by them. Anna's speech delivery similarly conveys a multi-layered stance on her experience. She encapsulates this in the SXB-contrast, conveying that her experience can be regarded as "silly"- and therefore taken less than seriously-whilst also maintaining that it was "important" to her at the time of the reported events.

Through laughter, modulations in voice quality, and the SXB-contrast, Anna shows that she holds a multi-faceted view of her experience in retrospect; she establishes it as "important" without, at the same time, making too much of it. This supports our claim that clients use SXBcontrasts to uphold the significance of their experience whilst showing awareness that it can be heard and evaluated in different ways. The difference between the laughter and the SXBcontrast is that, with SXB-contrasts, clients make this explicit.

In 11 out of the 21 cases in our collection, SXB-contrasts are associated with laughter in the client's talk (extracts 5 and 9, shown later, are additional examples). Extract 4 is another example; here, the client, Fran, has been talking about feeling inadequate and not being able to relate to the success that she has had more recently.

Extract 4. 'Fran'. Session 6, 19:31-20:56. Therapist B.

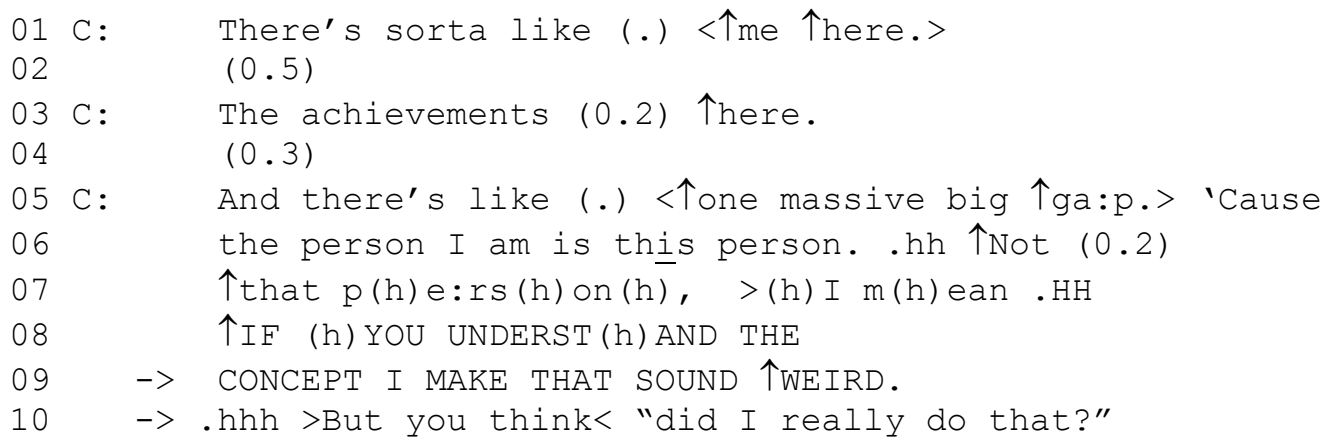


In Extract 4, Fran incorporates several bursts of laughter into her talk about how she is unable to recognise her own achievements (lines 7-8). From line 8, Fran shifts from talking about her experience to addressing the therapist ("if you understand the concept") to then producing a retrospective SXB-contrast. She does so with an increase in voice volume, shown through uppercase in the transcript. Fran uses practices of speech delivery to convey a stance on her own talk; with her laughter, she shows that she can take her own situation lightly. This dual perspective - a troubling subjective experience, which is treated somewhat lightly-is then encapsulated in the SXB-contrast (line 9-10). With the 'sounds X' part of the contrast, Fran displays awareness that her self-description can be received in a less sympathetic way; "weird" proposes that the experience may not be readily recognisable to others. "I make that sound weird" allows for the possibility that Fran is part of the audience that could find her talk "weird". In doing so, she conveys a multi-faceted perspective on her own experience. Notably, this fits with the nature of her emotional disclosure, which is already about a split subjective experience; her own poor self-image (line 1 and 5-7) being incompatible with her achievements or the person capable of achieving them (line 3). The 'but Y' part of the contrast ("but you think 'did I really do that?'”, line 10) supports the reality of the experience Fran has described (i.e., not recognising herself as the person capable of certain achievements; lines 1-7). The use of the generic "you" further supports the recognisability of the experience by framing it as one that others could potentially have.

The co-occurrence of SXB-contrasts with the practices of speech delivery examined in this section supports the claim that SXB-contrasts convey a multi-faceted perspective on an aspect of the client's experience. Clients voice a personally significant experience whilst framing it as vulnerable to an unsympathetic reception. In this way, they establish it as delicate.

\subsection{SXB-contrasts as markers of delicacy: evidence from clients' self-repair}

Clients sometimes introduce SXB-contrasts in their talk through "parenthesizing repair" operations (Schegloff, 2013; see also Mazeland, 2007). They suspend the production of a turn in progress, insert the SXB-contrast, and then observably resume the suspended talk. These same-turn self-repair operations support the argument that clients use SXB-contrasts to mark a part of their talk as delicate.

In Extract 5, the therapist suggests that it might be difficult for the client (Aisha) to trust her sufficiently (lines 1-2) to be able to explore Aisha's difficulties.

Extract 5. 'Aisha'. Session 5, 45:03-45:57. Therapist B.

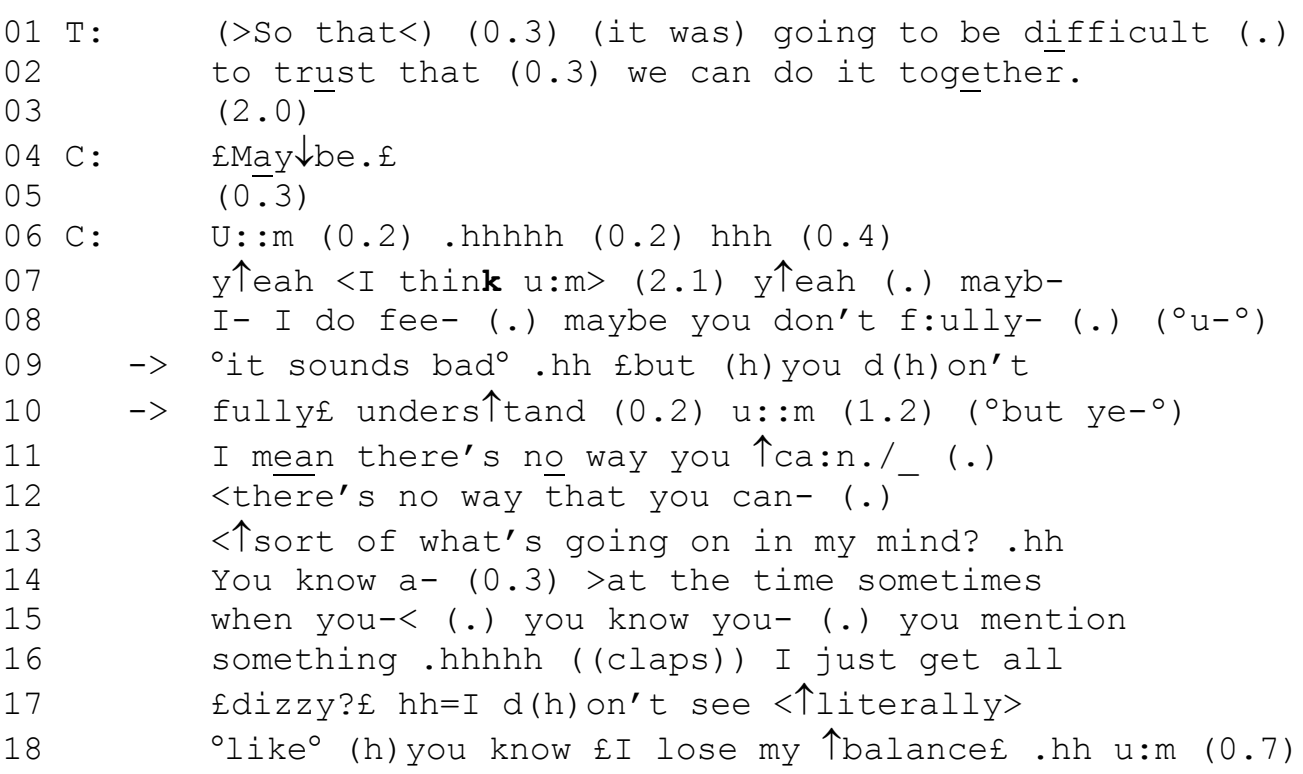




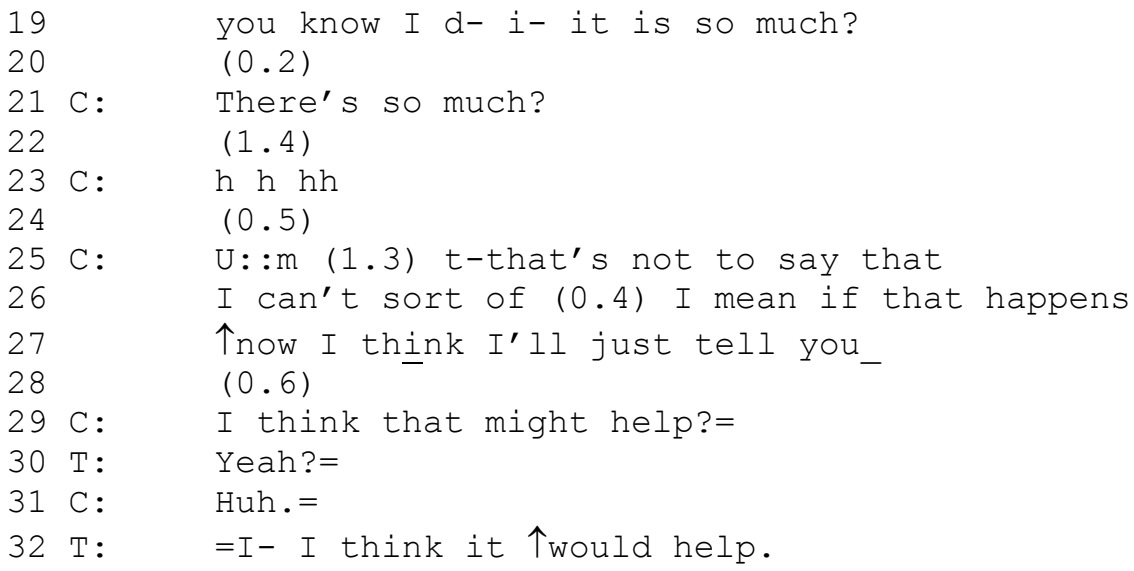

Aisha initially responds with a cautious "maybe" (line 4). After a silence (line 5) and some hesitations (line 6), Aisha confirms ("yeah", line 7) and then elaborates her perspective (lines 9-10). At lines 7-8, Aisha is arguably on her way to articulating this utterance ("mayb-II do fee- (.) maybe you don't f:ully- (.) ( $\left.\left({ }^{\circ} \mathrm{u}^{\mathrm{o}}\right)^{\text {") }}\right)$. She cuts it off and inserts a prospective SXBcontrast as a parenthetical remark before delivering the projected delicate item (that she feels the therapist may not be able to understand her). The 'sounds X' part of the contrast conveys the judgment that what she is about to say "sounds bad". The projected delicate item is then delivered as the 'but Y' part of the contrast ("but you don't fully understand").

To further clarify, we are aware that the client's turn containing the SXB-contrast is interspersed with several repair operations. Our point is more specific: at lines 6-7, Aisha observably starts and abandons what can be a version of what will turn out to be her claim that the therapist may not fully understand her (specifically, at line 8, "maybe you don't fully [understand me]"). She suspends this version to insert "it sounds bad but" (line 9). Therefore, the SXB-contrast is introduced here as the outcome of a repair operation. Aisha produces her statement about the therapist's lack of understanding as part of an SXB-contrast after showing that she could have - but selected not to - deliver it as a more straightforward (less qualified) statement. This analysis also supports the proposal that "it sounds bad" prospectively qualifies the upcoming "you don't fully understand" rather than being a retrospective comment on the therapist's turn at lines 1-2.

Aisha deploys multiple resources to deliver a delicate action-confirming the therapist's suggestion that she (Aisha) might not trust her. Aisha delays confirming her reservation about the therapeutic relationship - with the cautious "maybe" and the audible hesitations at lines 5-6. The SXB-contrast further delays the expression of such reservation, thereby marking its delicacy (Silverman \& Peräkylä, 1990; Weijts et al., 1993). The repair operation, with which Aisha inserts the SXB-contrast, reflexively marks the projected item as problematic - which is consistent with its disaffiliative implications for the relationship with the therapist. The insertion of the SXB-contrast enables Aisha to prospectively voice an unsympathetic hearing of the projected delicate item. In doing so, she exhibits awareness of the potentially disaffiliative nature of her remark and she displays sensitivity towards the therapist (the target of the remark).

This analysis supports our account of SXB-contrasts. Clients use them to mark a part of their talk as delicate. They do so by voicing an unsympathetic reception of that talk, and the perspective conveyed therein, whilst also supporting its significance. In doing so, they also show that they hold a multi-faceted perspective on their own experience, as conveyed through that talk. 
Burdett, Pino, Moghaddam, \& Schröder (2019). It sounds silly now, but it was important then

\subsection{SXB-contrasts as markers of delicacy: evidence from therapist responses}

A conventional way of validating an analysis in CA is the next-turn proof procedure: examining how recipients respond to the action that is the focus of the analysis (ten Have, 2007). We examined therapists' responses to clients' SXB-contrasts to see whether they exhibited an orientation to the functions we have attributed to them.

One difficulty in this analysis is that clients' SXB-contrasts are often embedded within extended turns-at-talk. Therefore, therapists' subsequent talk follows whatever part of clients' talk comes after the SXB-contrast. Therapists address the overall action conveyed by the client's turn with no observable orientation to the client's use of an SXB-contrast. There are a few cases where therapists respond to clients after they have used an SXB-contrastsometimes after an intervening gap but without further client talk after the contrast; these support our proposal that SXB-contrasts are designed to uphold the significance of the client's experience.

Extract 6. 'Alice'. Session 10, 4:41-7:19. Therapist C.

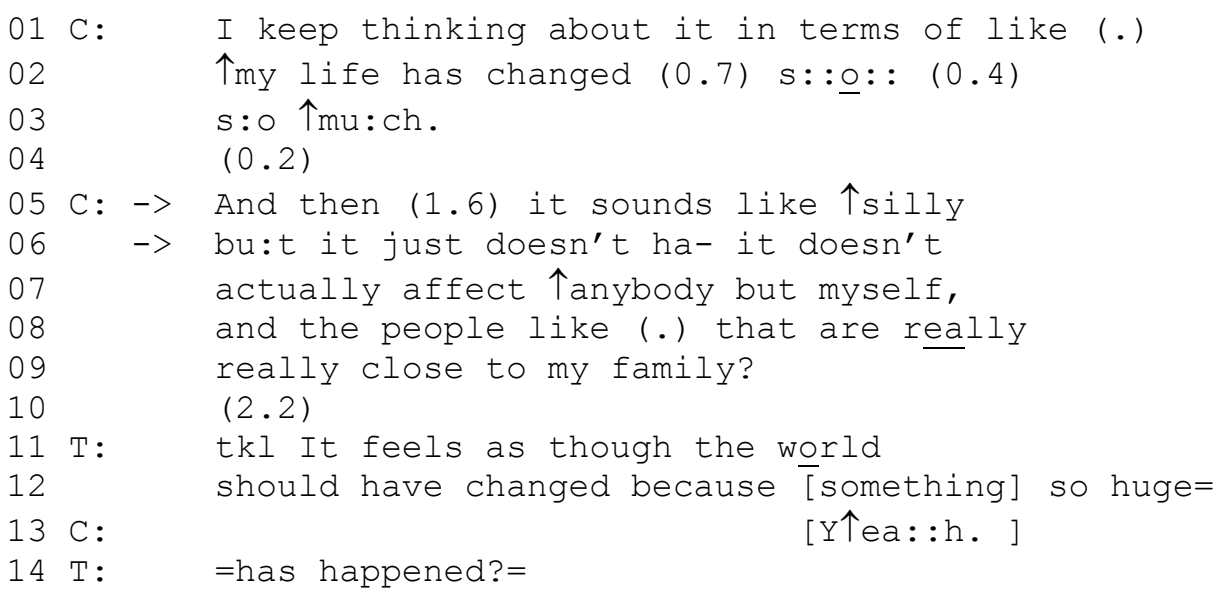

In Extract 6, Alice produces a prospective SXB-contrast (lines 5-6), voicing a sense of bewilderment at her own expectation that other people should be affected by the death of her father in the same way she is. The SXB-contrast is produced within a turn that reaches a point of possible completion-hence making it relevant for the therapist to take a turn-at the end of line 9. After a 2.2-second silence, the therapist offers an interpretation (lines 11-14; Peräkylä, 2013).

The therapist's interpretation supports the validity of Alice's experience. Alice has expressed the feeling that the death of her father should have an impact on other people's lives beyond her family; she has commented that this "sounds silly" (including to her, insofar as she can be understood to be part of the audience to whom her experience may sound silly $)^{2}$. However, she has gone on to uphold the significance of that feeling (with the 'but Y' part of the contrast). With her interpretation, the therapist validates Alice's experience (lines 11-14), tacitly rejects the possibility that the experience sounds silly, and thereby orients to Alice's turn as implementing the action of supporting the significance of that experience.

There are three cases in our collection where therapists speak before clients have completed the SXB-contrast; more precisely, therapists start to talk in a silence following "but". Two of these cases further support our analysis whereas the third shows a different pattern. We examine them in what follows.

\footnotetext{
2 This echoes Fran's split subjective experience from Extract 4 and how some of the clients convey a separation between 'thinking' and 'feeling' when reflecting on their experiences.
} 
Burdett, Pino, Moghaddam, \& Schröder (2019). It sounds silly now, but it was important then

In Extract 7, the client (Liv) has been talking about the death of her father and about how she has been struggling to adjust.

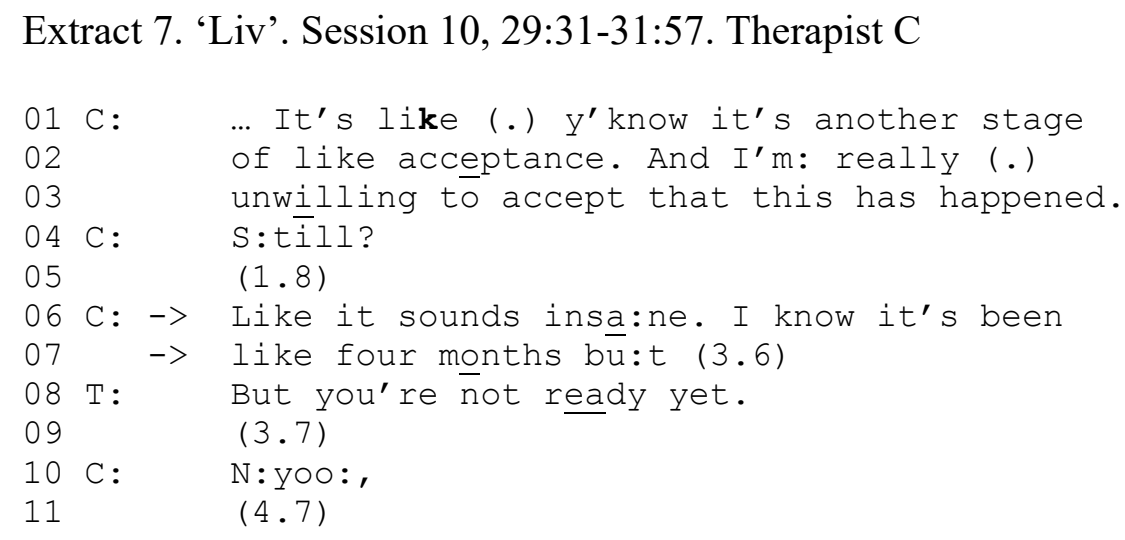

Liv describes her unwillingness to accept the death of her father whilst establishing acceptance as a normative outcome she might be expected to achieve (she implies that she will eventually accept it, lines 1-4). After a 1.8-second silence (line 5), Liv starts an SXB-contrast. She suspends its production after the "but"-component, and a 3.6-second silence emerges (line 7). The therapist completes the contrast on Liv's behalf (with a recycling of the "but" component and pronominal adjustment: "but you're not ready yet"). Prior research has shown that recipients can use candidate turn completions to assist speakers in articulating something delicate (Lerner, 2013). By completing the SXB-contrast, the therapist displays an understanding that it is designed to mark an aspect of Liv's experience as delicate-insofar as it can attract an unsympathetic hearing-whilst supporting its significance. Notably, the therapist demonstrates appreciation of both aspects of Liv's experience (as expressed throughout lines 1-7): that she has not accepted the death of her father and that such acceptance is an outcome that she can be expected to achieve ("but you're not ready yet", line 8).

We have observed that clients do not use SXB-contrasts to retract or abandon a point they have made or are (projectably) going to make but, rather, to support it. By completing Liv's turn, the therapist orients precisely to this function of the SXB-contrast. She anticipates that Liv is on her way to reaffirm the reality of her experience of grief (already stated at lines 1-3) rather than to deny it; Liv confirms the therapist's understanding (line 10).

In Extract 8, the client (Paul) has been discussing how he manages his anxiety about being ignored by other parents when he is dropping his children off at school.

Extract 8. 'Paul'. Session 1, 11:52-14:12. Therapist D.

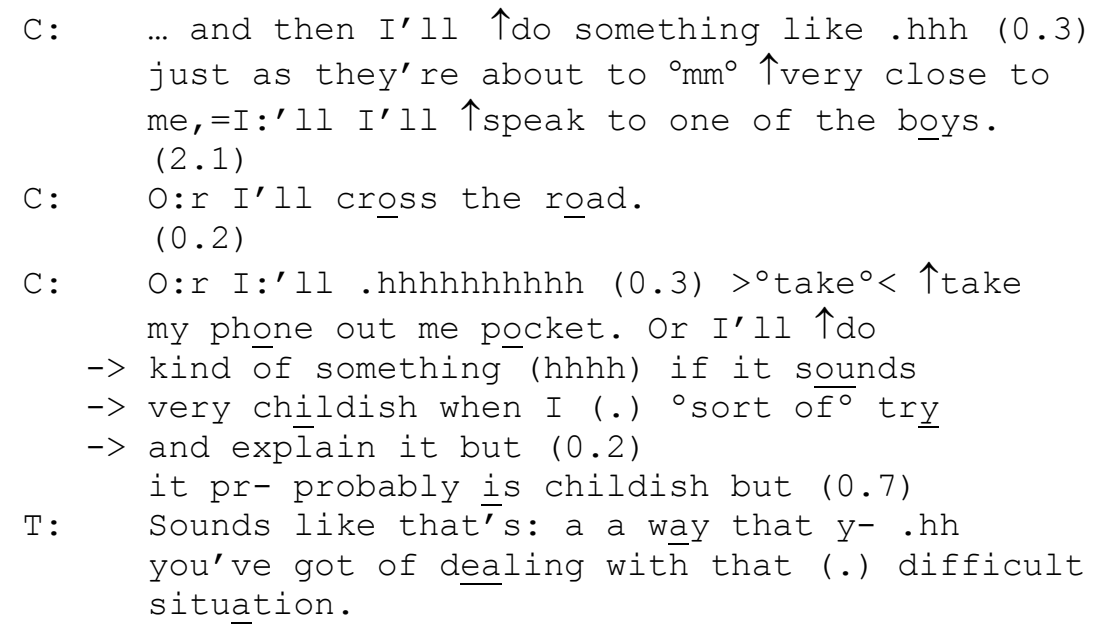


Burdett, Pino, Moghaddam, \& Schröder (2019). It sounds silly now, but it was important then

$16 \quad(0.7)$

Paul explains how he prevents situations where he could be ignored by otherwise occupying himself ("I'll speak to one of the boys", line 3). He describes two additional strategies he uses at lines 5-8. He starts and abandons the report of another strategy ("or I'll do kind of something", lines 8-9) and starts an SXB-contrast ("it sounds very childish when I sort of try and explain it but", line 9). He leaves a 0.2-second silence after the "but" component. He then repairs the 'sounds X' part of the contrast to propose that his experience "pr- probably is [rather than sounds] childish" (line 12). This makes this case partly different from the one considered above. Whereas "sounds childish" allows for the possibility that Paul holds this view about his own experience (that is, his own talk could sound childish to him as well as to others), "it probably is childish" more definitely constructs that judgment as coming from Paul. There is also an element of self-deprecation which may account for what happens next.

Paul suspends the production of the turn in progress after "but" (a 0.7-second silence emerges). The therapist intervenes at this point. He ties his response to the 'sounds X' part of the contrast by recycling the word "sounds". He validates Paul's experience (described at lines 1-8) as a meaningful response to a difficult situation - therefore, not "childish". By proposing a characterisation that contrasts with Paul's own characterisation ("childish"), the therapist may be countering its self-deprecatory element (Pomerantz, 1984). Important for our analysis is that the therapist's supportive intervention (validating Paul's experience) may display his understanding of the function of Paul's projected contrast; that is, at the point where Paul has voiced an unsympathetic reception of his own experience, "but" (line 12) projects a contrastive perspective which may (re)affirm the significance of that experience. The therapist therefore supports the action Paul has started to implement through the (modified) SXB-contrastvalidating his own experience whilst voicing an unsympathetic reception of it.

Extracts 6,7 and 8 suggest that therapists orient to and support the function of SXBcontrasts; that is, they collaborate with the clients' efforts to uphold the significance of their experience. Interestingly, therapists do not comment on or enquire about the 'sounds $X$ ' part of the contrast (i.e., hypothetically, a therapist could ask a client why they find that their experience sounds X, e.g., silly). Only one case in our collection deviates from this pattern. In Extract 9, Paul (the same client as in Extract 8) has been talking about the fact that he counts items, such as the rings on his curtains (lines 1-12).

Extract 9. 'Paul'. Session 11, 2:35-4:50. Therapist D

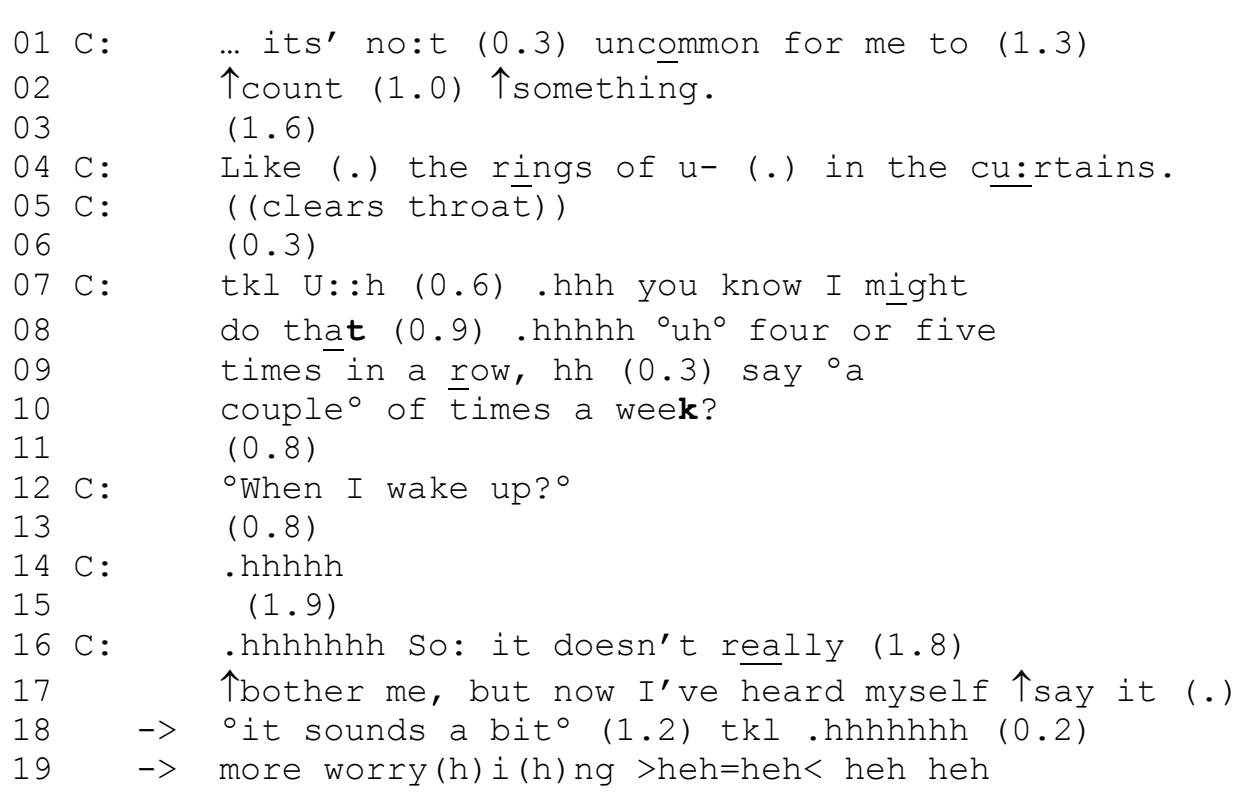


Burdett, Pino, Moghaddam, \& Schröder (2019). It sounds silly now, but it was important then

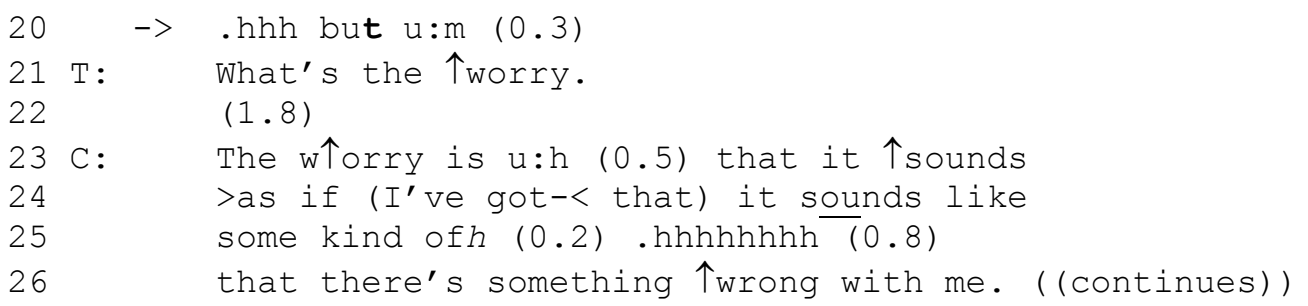

From line 16, Paul starts to draw a conclusion on the experience he has reported ("it doesn't really bother me") and then starts an SXB-contrast (lines 17-20). Similar to extracts 7 and 8 , the therapist starts to talk in the emerging silence after the "but" component (more precisely, after "but uhm + [silence]", line 20). However, the therapist's action here is different. In extracts 7 and 8, the therapist validates the client's experience. In Extract 7, this takes the form of completing the 'but $\mathrm{Y}$ ' part of the contrast on the client's behalf (thereby tacitly countering the unsympathetic reception of the client's experience). In Extract 8, the therapist produces an interpretive statement which supports the validity of the client's experience (thereby also tacitly countering the unsympathetic reception of that experience; see also Extract 6). By contrast, the therapist in Extract 9 invites Paul to expand upon the 'sounds $X$ ' part of the SXB-contrast - that is, the voiced reception of his experience. We account for this pattern with reference to two elements in the design of Paul's SXB-contrast.

First, whereas in the other cases clients use the 'sounds X' part of the contrast to voice an unsympathetic reception of their talk (respectively: silly, ungrateful, weird, bad, silly, insane, and childish), Paul characterises it as "worrying". Second, whereas in the other cases clients voice the perspective of an audience (to whom their talk may 'sound X') and the design of the SXB-contrast sometimes allows for the possibility that the client themselves are part of that audience (i.e., their experience may 'sound X' to them, not only to others), the pre-framing of the SXB-contrast in Extract 9 ("now I've heard myself $\uparrow$ say it") more strongly places Paul within the audience whose reaction he voices. These elements appear to infuse Paul's SXBcontrast with a different action import: conveying his own concern about the experience he has just voiced (rather than just support its significance, as in the other cases). This may invite, or at least warrant, the therapist's solicitation to expand upon that concern. These aspects suggest that Extract 9 is a boundary case (Schegloff, 1997), or perhaps a negative case altogether, where the SXB-contrast implements a different action (i.e., communicating a concern).

In summary, therapist responses support the claim that clients use SXB-contrasts to uphold the significance of their experience against a voiced unsympathetic reception of it. Therapists validate the client's experience (conveyed by the 'but $Y$ ' part of the contrast) and thereby tacitly counter the contrastive perspective voiced in the 'sounds $\mathrm{X}$ ' part (extracts 6,7 , and 8).

\section{Discussion}

Psychotherapy clients use SXB-contrasts to mark a part of their talk as delicate. They do so by voicing an unsympathetic reception of their talk whilst supporting its significance. Our findings augment understandings of clients' use of meta-talk in psychotherapy. Unlike the cases of narrative reflexivity examined by Auburn (2005), the clients in our data generally do not use SXB-contrasts to discount the validity of a problematic hearing of their own talk. Rather, they exhibit awareness that their experience can be seen from different angles. It has personal significance, as seen from the client's unique standpoint, but it can also be judged unsympathetically from the perspective of a more detached audience. This finding fits with a difference between the psychotherapy setting we have examined and the sex offender group therapy examined by Auburn (2005). In the latter, group members monitored each individual offender's talk to pick up on signs of non-compliance with the normative expectations associated with the rehabilitation programme. Offenders exhibited alertness to the possibility 
that parts of their talk could attract negative inferences. In our data, clients do not display this kind of preoccupation. Their use of meta-talk appears to reflect a more general orientation to how their experience - as conveyed through their talk - can be received in different ways, depending on the perspective being adopted. We believe that the distinction is important. The clients in our data generally do not take a defensive stance against an anticipated hostile hearing of their talk (they generally do not discount its validity; for a possible exception, see Extract 3 above). Rather, they voice an unsympathetic reception of their experience and use it as the background against which the significance of that experience can be properly appreciated (that is, the experience is important despite the fact that it can be heard as "X"). Additionally, in most cases the SXB-contrast raises the possibility that the client's talk sounds " $\mathrm{X}$ " to themselves (not only to others). In doing so, clients may be doing more than supporting the significance of their experience; they may also be conveying that they are ambivalent towards it.

Our findings strongly resonate with Jefferson's (2004b) work on the contrast structure "At first thought X, then I realized Y" (see also her reference to Sacks' work on "We were going to X"; Sacks, 1992):

"In his 1971 lecture, Sacks speaks of the naming of the rejected alternative as showing one's "commitment to the normal" [...] naming a rejected alternative provides that what happened here is distinctly unusual, plus that unusual, odd events don't count." (Jefferson, 2004b, pp. 154-155).

The clients in our data do not generally reject the " $X$ " alternative. However, by voicing that alternative they also show "commitment to the normal". Intuitively, if someone has an unusual experience, they should feel comfortable to discuss it in therapy. With SXB-contrasts, clients do report such experiences, but they also treat them as having the potential to be regarded as weird, silly, insane, and so on. In reporting their experiences, clients display awareness of their unusual nature and thereby demonstrate that their perceptions are firmly grounded in everybody's ordinary reality (Sacks, 1984). They exhibit awareness of social standards for what counts as a normal experience. SXB-contrasts therefore help clients perform an important piece of "face-work" in therapy (Goffman, 1955).

The latter observations connect to our sense that SXB-contrasts are not exclusively designed to anticipate the therapist's unsympathetic reception of the client's talk but, rather, to display an orientation to a possible reception of the client's talk in a broader sense - pertaining to what we have termed an unsympathetic audience. SXB-contrasts may therefore be a way in which clients bring into their therapy an orientation to wider socio-cultural expectations about what count as intelligible and appropriate experiences and actions. This point connects to the possibility that SXB-contrasts are not native to therapeutic interactions but, rather, that they are used more broadly, across a range of ordinary and institutional settings. We were unable to explore this possibility within the limits of the current study and we hope to do so in the future.

We have proposed that clients use SXB-contrasts to voice a generalised hearing of their talk. Clients display an orientation to how their talk can be received and judged by others, where the sense of "others" extends beyond the "particular others" interacting with them (Sacks et al., 1974), that is, the therapist, to include a broader audience (including the clients themselves). Seen in this way, clients' meta-talk - in the case of SXB-contrasts - is not exclusively deployed to anticipate a possible reception of their talk by the therapist. By evoking a more generalised hearing of their talk, clients sometimes suggest that they are amongst those hearers who could receive that talk in an unsympathetic way (e.g., that they can hear their own talk as "silly" or "weird" whilst trying to convey its importance). In these cases, the boundary between self and other starts to blur, with clients animating and partly adopting the perspective of the audience who could hear and judge their talk (see Mead, 1934/62). In these ways, clients manifest awareness of the multi-faceted nature of their own experience. We believe this is an 
important resource that clients use to foster a sense of intersubjectivity within psychotherapy and, ultimately, to solve the practical problem that troubles-tellers face in trying to convey the meaning of their experiences to their recipients (Jefferson, 1988).

Our findings have implications for understandings of delicacy in social interaction. We have shown that speakers deploy a constellation of practices-including aspects of speech delivery and meta-talk - to endow a described experience with multiple meanings. We have shown ways in which clients convey that their experience, which they describe as important, could also be taken less than seriously (e.g., through laughter; Jefferson, 1984). SXB-contrasts encapsulate this multi-layered perspective more explicitly by labelling an experience both as important and as having the potential to attract less benign evaluations. In these ways, clients can share with their therapists experiences that might be regarded as socially awkward or difficult to fathom - for these reasons, delicate to articulate.

\section{Acknowledgements}

The authors would like to thank Charles Antaki, Paul Drew, Joe Ford and members of the DARG research group at Loughborough University for feedback on an early version of the analyses leading up to this paper. Rein Sikveland for advice on how to describe some of the phonetic qualities of focal segments of the clients' talk. Sue Weeler for facilitating access to the corpus of recordings used. Two anonymous reviewers for their generous and helpful comments and suggestions.

\section{References}

Auburn, Timothy. (2005). Narrative reflexivity as a repair device for discounting "cognitive distortions" in sex offender treatment. Discourse \& Society, 16, 697-718.

Goffman, Erving. (1955). On Face-Work. Psychiatry, 18(3), 213-231.

Goffman, Erving. (1959). The Presentation of the Self in Everyday Life. NY, NY: Doubleday Hepburn, Alexa., \& Bolden, Galina. B. (2013). The Conversation Analytic Approach to Transcription. In J. Sidnell \& T. Stivers (Eds.), The Handbook of Conversation Analysis (pp. 57-76). Boston: Wiley-Blackwell.

Heritage, John. (1984). Garfinkel and Ethnomethodology. Cambridge: Polity Press.

Hewitt, John. P., \& Stokes, Randall. (1975). Disclaimers. American Sociological Review, $40(1), 1-11$.

Holt, Elizabeth. (2012). Using Laugh Responses to Defuse Complaints. Research on Language \& Social Interaction, 45(4), 430-448.

Hutchby, Ian., \& Wooffitt, Robin. (2008). Conversation Analysis (2nd ed.). Cambridge: Polity. Jefferson, Gail. (1981). The rejection of advice: Managing the problematic convergence of a 'troubles-telling' and a 'service encounter'. Journal of Pragmatics, 5(5), 399-422.

Jefferson, Gail. (1984). On the organization of laughter in talk about troubles. In J.M. Atkinson and J.C. Heritage (Eds.) Structures of social action: Studies in conversation analysis (pp.346-369). Cambridge, UK: Cambridge University Press

Jefferson, Gail. (1988). On the Sequential Organization of Troubles-Talk in Ordinary Conversation. Social Problems, 35(4), 418-441.

Jefferson, Gail. (2004a). Glossary of transcript symbols with an introduction. In Lerner, G. H. (Ed.), Conversation Analysis: Studies from the first generation (pp. 13-23). Philadelphia: John Benjamins.

Jefferson, Gail. (2004b). "At first I thought": A normalizing device for extraordinary events. In G. Lerner (Ed.), Conversation analysis: Studies from the first generation (pp. 131-167). Amsterdam: Benjamins.

Lerner, Gene. H. (2013). On the place of hesitating in delicate formulation: a turnconstructional infrastructure for collaborative indiscretion. In Hayashi, M., Raymound, 
Burdett, Pino, Moghaddam, \& Schröder (2019). It sounds silly now, but it was important then

G., \& Sidnell, J. (Eds.), Conversational Repair and Human Understanding (pp. 95-134). Cambridge: Cambridge University Press.

Logren, Aija., Ruusuvuori, Johanna., \& Laitinen., Jaana. (2017). Self-reflective talk in group counselling. Discourse Studies, 19(4), 422-440

Lucy, John. A. (1993). Reflexive Language: Reported Speech and Metapragmatics. (John. A. Lucy, Ed.). Cambridge: Cambridge University Press.

Madill, Anna., Widdicombe, Sue., \& Barkham, Michael. (2001). The Potential of Conversation Analysis for Psychotherapy Research. The Counseling Psychologist, 29(3), 413-434. h

Mandelbaum, Jenny. (2013). Storytelling in Conversation. In Sidnell, J \& Stivers, T. (Eds.), Handbook of conversation analysis (pp. 492-508). Oxford: Wiley-Blackwell.

Mazeland, Harrie. (2007). Parenthetical sequences. Journal of Pragmatics, 39m 1816-1869.

Mead, George. Herbert. (1934/62). Mind, Self and Society. Chicago: University of Chicago Press

Peräkylä, Anssi. (2013). Conversation Analysis in Psychotherapy. In Sidnell, J., \& Stivers, T. (Eds.), The Handbook of Conversation Analysis (pp. 551-574). Chichester: WileyBlackwell.

Pomerantz, Anita. (1984). Agreeing and disagreeing with assessments: Some features of preferred/dispreferred turn shapes. In Heritage, J., \& Atkinson, M. (Eds.), Structures of Social Action: Studies in Conversation Analysis (pp. 57-101). Cambridge: Cambridge University Press.

Potter, Jonathan., \& Hepburn, Alexa. (2000). Putting aspiration into words: 'Laugh particles', managing descriptive trouble and modulating action. Journal of Pragmatics, 42, pp. 1543-1555. https://doi.org/10.1016/j.pragma.2009.10.003

Sacks, Harvey. (1984). On doing "Being Ordinary". In J. K. Atkinson \& J. Heritage (Eds.), Structures of Social Action: Studies in Conversation Analysis (pp. 413-429). Cambridge: Cambridge University Press.

Sacks, Harvey. (1992). Lectures on Conversation. 2 vols. Oxford: Blackwell.

Sacks, Harvey., Schegloff, Emmanuel. A., \& Jefferson, Gail. (1974). A simplest systematics for the organization of turn-taking for conversation. Langauge, 50(4), 696-735.

Schegloff, Emmanuel. A. (1991). Conversation analysis and socially shared cognition. In L. B. Resnick, Levine, J. M., \& Teasley, S. D. (Eds.) Perspectives on Socially Shared Cognition (pp. 150-171). Washington, DC: American Psychological Association.

Schegloff, Emmanuel. A. (1996). Confirming Allusions: Toward an Empirical Account of Action. American Journal of Sociology, 102(1), 161-216. http://doi.org/10.1086/230911

Schegloff, Emmanuel. A. (1997). Practices and actions: Boundary cases of other-initiated repair. Discourse Processes, 23(3), 499-545.

Schegloff, Emmanuel. A. (2007). Sequences Organization In Interaction: A Primer in Conversation Analysis. Cambridge: Cambridge University Press.

Schegloff, Emmanuel. A. (2013). Ten operations in self-initiated, same-turn repair. In M. Hayashi, G. Raymond, \& J. Sidnell (Eds.), Conversational Repair and Human Understanding (pp. 41-70). Cambridge: Cambridge University Press.

Silverman, David., \& Peräkylä, Anssi. (1990). AIDS counselling: the interactional organisation of talk about "delicate" issues. Sociology of Health and Illness, 12(3), 293-318.

ten Have, Paul. (2007). Doing Conversation Analysis: A Practical Guide (2nd ed.). London: SAGE Publications.

Verschueren, Jef. (2000). Notes on the role of metapragmatic awareness in language use. Pragmatics, 10(4), 439-456.

Voutilainen, Liisa., \& Peräkylä, Anssi. (2014). Therapeutic Conversation. In J. Östman \& J. Verschueren (Eds.), Handbook of Pragmatics Online. John Benjamins.

Weijts, Wies., Houtkoop, Hanneke., \& Mullen, Patricia. (1993). Talking Delicacy: Speaking about Sexuality during Gynaecological Consultations. Sociology of Health and Illness, $15(3), 295-314$. 